\title{
TEKANAN EKONOMI, COPING EKONOMI, DUKUNGAN SOSIAL, DAN KESEJAHTERAAN PEREMPUAN KEPALA KELUARGA
}

\author{
Rahmi Yulfa ${ }^{1^{*}}$, Herien Puspitawati ${ }^{2}$, Istiqlaliyah Muflikhati ${ }^{2}$ \\ ${ }^{1}$ Program Studi Magister Ilmu Keluarga dan perkembangan Anak, Sekolah Pascasarjana, \\ IPB University, Bogor 16880, Indonesia \\ ${ }^{2}$ Departemen IImu Keluarga dan Konsumen, Fakultas Ekologi Manusia, \\ IPB University, Bogor 16880, Indonesia \\ *)E-mail: rahmi_yulfa@apps.ipb.ac.id
}

\begin{abstract}
Abstrak
Keluarga yang dikepalai perempuan rentan terhadap kemiskinan yang tak lain disebabkan oleh faktor pendapatan yang rendah dan lingkungan yang tidak mendukung. Penelitian ini menggunakan desain crosssectional dan diteliti secara kuantitatif yang bertujuan untuk menganalisis pengaruh tekanan ekonomi, coping ekonomi, dan dukungan sosial terhadap kesejahteraan perempuan kepala keluarga. Penelitian ini melibatkan 100 perempuan yang bercerai dan memiliki anak di Jawa Barat dengan menggunakan non-probability voluntary sampling. Berdasarkan hasil penelitian, rata-rata usia responden adalah 39 tahun dan lama menjanda adalah 4 tahun. Sebagian besar responden memiliki pekerjaan tidak tetap dengan pendapatan di bawah garis upah minimum provinsi. Lebih dari setengah $(66,0 \%)$ responden memiliki rasio aset lebih sedikit daripada utang dan semua $(100,0 \%)$ responden memiliki utang. Variabel tekanan ekonomi, coping ekonomi, dukungan sosial, dan kesejahteraan berada pada kategori sedang. Karakteristik seperti pekerjaan dan lama menjanda berpengaruh positif dan negatif signifikan terhadap kesejahteraan subjektif. Coping ekonomi berpengaruh negatif signifikan terhadap kesejahteraan subjektif. Dukungan sosial juga berpengaruh positif siginifikan terhadap kesejahteraan subjektif. Pekerjaan dan rentang lama menjanda menjadi faktor yang dapat memengaruhi tingkat kesejahteraan keluarga. Kesejahteraan pun dapat diperoleh jika perempuan kepala keluarga tidak memiliki utang. Semakin sedikit coping ekonomi yang dilakukan oleh perempuan kepala keluarga, serta semakin banyak dukungan sosial yang didapatkan akan meningkatkan tingkat kesejahteraannya.
\end{abstract}

Kata kunci: coping ekonomi, dukungan sosial, kesejahteraan, perempuan kepala keluarga, tekanan ekonomi

\section{Economic Pressure, Economic Coping, Social Support, and Welfare of Female-Headed Family}

\begin{abstract}
The female-headed family is vulnerable to poverty due to low income and an unsupportive environment. This study aims to analyze the effect of economic pressure, economic coping, and social support on the well-being of the female-headed family. This study used a cross-sectional design with a quantitative approach involving 100 divorced women with children in West Java using voluntary non-probability sampling. Based on the research, the average age of the respondents was 39 years, and the length of widowhood was four years. Most respondents had precarious jobs with incomes below the provincial minimum wage line. More than half of respondents had a smaller asset ratio than debt, and all respondents had debt. The variables of economic pressure, economic coping, social support, and welfare were in the medium category. Characteristics such as occupation and length of widowhood had a significant negative and positive effect on subjective well-being. Economic coping had a significant negative effect on subjective well-being. Social support also had a positive effect on subjective wellbeing. Age and length of time affected the level of well-being. Well-being could also be obtained if the female head of the family did not have debt. The less economic coping that female-headed families did and the more social support they received would increase their level of well-being.
\end{abstract}

Keywords: economic coping, economic pressure, female-headed families, social support, well-being

\section{PENDAHULUAN}

Keluarga adalah unit sosial-ekonomi terkecil dalam masyarakat yang merupakan landasan dasar dari semua institusi. Keluarga merupakan kelompok primer yang terdiri dari dua atau lebih orang yang mempunyai jaringan interaksi interpersonal, hubungan darah, hubungan perkawinan, dan adopsi (Puspitawati, Simanjuntak, \& Hayati 2012). Pendekatan struktural fungsional merupakan salah satu pendekatan teori sosiologi yang telah 
diterapkan dalam institusi keluarga. Struktural fungsional memandang masyarakat sebagai suatu sistem yang terintegrasi secara fungsional ke dalam bentuk suatu ekuilibrum (Parson, 1937). Rumah tangga tidak seluruhnya dikepalai oleh laki-laki namun juga dikepalai oleh perempuan. Kepala keluarga adalah pencari nafkah dalam keluarga. Banyaknya keluarga dikepalai oleh perempuan salah satunya disebabkan oleh tingginya tingkat perceraian yang terjadi di kalangan masyarakat Indonesia. Jumlah perceraian meningkat di Indonesia dari tahun ke tahun (BPS, 2018). Peningkatan jumlah perceraian di Indonesia terjadi pada periode 2016-2018 (Kemenag, 2019). Pada 2016 angka perceraian mencapai 365.654 perkara, tahun 2017 sebanyak 380.723 perkara, dan pada tahun 2018 sebanyak 419.268 perkara. Indonesia memiliki rumah tangga yang berjumlah 10.3 juta dan diantaranya sebanyak 1.617 .000 rumah tangga dikepalai oleh perempuan (BPS, 2020).

Perempuan kepala keluarga ini adalah perempuan bercerai yang menggantikan dan menjalankan peran seorang laki-laki sebagai pencari nafkah. Menurut komunitas PEKKA atau Komunitas Pemberdayaan Perempuan Kepala Keluarga (2019), yang merupakan yayasan yang fokus mengorganisasikan dan melakukan pendampingan pada kelompok perempuan kepala keluarga, perempuan kepala keluarga adalah perempuan yang melaksanakan peran dan tanggung jawab sebagai pencari nafkah, pengelola rumah tangga, penjaga keberlangsungan kehidupan keluarga, dan pengambil keputusan dalam keluarga, termasuk perempuan yang bercerai, yang ditinggal oleh suami, yang suaminya meninggal dunia, tidak menikah dan memiliki tanggungan keluarga, yang memiliki suami namun karena satu hal suami tidak dapat menjalankan fungsinya sebagai kepala keluarga, dan perempuan yang bersuami namun suami tidak hidup dengannya secara berkesinambungan karena merantau atau poligami. Komunitas PEKKA yang bekerja sama dengan social monitoring and early response unit (SMERU) menyatakan bahwa keluarga yang dipimpin oleh perempuan, selain sebagai pencari nafkah utama, perempuan ini secara garis besar berperan juga sebagai pengambil keputusan dalam keluarga seperti penggunaan anggaran rumah tangga untuk memenuhi kebutuhan sehari-hari, penggunaan dana bantuan pemerintah, urusan kesehatan anggota keluarga, pendidikan dan pernikahan anak, pembelian aset, serta peminjaman uang dan kredit (PEKKA \& SMERU, 2014). Survei yang dilakukan oleh sistem pemantauan kesejahteraan berbasis komunitas PEKKA pada tahun 2012 menunjukkan 71 persen keluarga di kesejahteraan terendah $(40 \%$ terbawah) dan keluarga ini dikepalai oleh perempuan. Provinsi Jawa Barat merupakan provinsi terbanyak ketujuh populasi perempuan sebagai kepala keluarga dengan jumlah mencapai 4.118 jiwa yang sudah terorganisir dan Provinsi Nusa Tenggara Barat merupakan provinsi yang paling banyak populasi perempuan sebagai kepala keluarganya sebanyak 6.673 jiwa yang telah terorganisir. Populasi perempuan kepala keluarga di Provinsi Jawa Barat tersebar dalam 7 kabupaten, 36 kecamatan, 81 desa/kelurahan, dan terdiri dari 155 kelompok dengan jumlah anggota serikat perempuan kepala keluarga yang terdata sebanyak 2.277 jiwa (PEKKA \& SMERU, 2014).

Keluarga yang dikepalai oleh perempuan bercerai mengalami permasalahan kesejahteraan lebih buruk dan lebih panjang dibanding keluarga yang dikepalai oleh laki-laki. Keluarga yang dikepalai oleh laki-laki yang bercerai mengalami masalah atau konsekuensi perceraian hanya dalam waktu jangka pendek, seperti dalam hal kesejahteraan subjektif, dibandingkan dengan keluarga yang dipimpin oleh perempuan (Leopold, 2018). Perempuan kepala keluarga yang baik bercerai mati atau hidup tidak memiliki perbedaan tingkat kesejahteraan subjektif (Miranda \& Amna, 2017). Rendahnya tingkat kesejahteraan keluarga yang dikepalai oleh perempuan disebabkan oleh tingkat pendidikan yang rendah sehingga perempuan kepala keluarga ini hanya bisa bekerja di sektor informal seperti buruh tani, pedagang, dan pengrajin dengan pendapatan rata-rata per hari hanya Rp10.000 (PEKKA \& SMERU, 2014). Rendahnya pendapatan menimbulkan permasalahan ekonomi dalam keluarga sehingga kesejahteraan bagi keluarga pun sulit tercapai. Keluarga yang dikepalai oleh perempuan memiliki permasalahan dalam hal ekonomi dan masalah rumah tangga lainnya (Dar, 2018). Tekanan ekonomi merupakan ketidakmampuan keuangan yang dirasakan oleh keluarga sehingga mengganggu pemenuhan kebutuhan anggota keluarga (Robila \& Krishnakumar, 2005). Semakin tingginya tingkat tekanan ekonomi maka tingkat kesehateraan pun akan semakin rendah (Puspitawati, Putri, Titipani, \& Khasanah, 2019). Selain itu, permasalahan ekonomi menjadi faktor penyebab terjadinya disfungsi dalam keluarga. Untuk itu, keluarga memerlukan coping ekonomi yang baik dan tepat. 
Ekonomi merupakan salah satu faktor yang dapat meningkatkan kesejahteraan keluarga. Keluarga merupakan unit ekonomi yang melakukan aktivitas guna memperoleh hasil yang diinginkan seperti kepuasan, tujuan, gaya hidup, standar hidup, kesejahteraan, kenyamanan, kemampuan, dan keterampilan untuk proses produksi dan konsumsi (Raz \& Bryant, 1990). Tekanan ekonomi dapat dilihat dari tingkat pendapatan, perubahan pendapatan yang semakin tidak memadai, dan pekerjaan yang tidak stabil (Raharjo, Puspitawati, \& Krisnatuti, 2015). Tekanan ekonomi dapat dipengaruhi oleh perbedaan wilayah, pendidikan kepala keluarga, dan modal finansial (Sabania \& Hartoyo, 2016). Keluarga yang mengalami tekanan ekonomi akan mengahadapi konflik rumah tangga yang lebih tinggi yang secara tidak langsung dapat meningkatkan depresi ibu dan menurunkan dukungan sosial (Robila \& Krishnakumar, 2005). Salah satu strategi yang dapat dilakukan agar dapat menurunkan tingkat tekanan adalah dengan melakukan koping atau strategi seperti coping ekonomi. Coping ekonomi merupakan cara dalam mengatasi krisis keuangan yang dialami oleh keluarga (Yilma et al., 2014). Coping ekonomi yang dilakukan oleh keluarga tergantung kepada sumber daya yang dimiliki; apabila memiliki aset yang banyak, seperti tanah, maka keluarga menjual tanah dalam melakukan coping ekonomi (Börner, Shively, Wunder, \& Wyman, 2015). Coping ekonomi keluarga terbagi ke dalam lima bagian, yakni: mengurangi konsumsi, menjual aset, meminjam, menjadi buruh, dan tidak ada respon coping (Yilma et al., 2014). Sementara Börner et al. (2015) membagi dimensi coping ekonomi menjadi lima dimensi, yakni: mengurangi konsumsi (reduced consumption), mengonsumsi produk sendiri (sayur, memancing ikan, dan lain sebagainya), menjual aset (memakai tabungan, tanah, dan lain sebagainya), mencari pekerjaan tambahan, dan mencari bantuan.

Keluarga yang dikepalai oleh perempuan memiliki permasalahan nonekonomi seperti kurangnya kepercayaan diri (Dar, 2018). Kurangnya kepercayaan diri serta tingkat pengetahuan yang rendah membuat perempuan kepala keluarga membutuhkan dukungan sosial untuk meningkatkan kesejahteraan keluarganya. Dukungan sosial berperan penting untuk meningkatan kepercayaan diri dan kepercayaan diri dapat ditingkatkan dengan bantuan lingkungan sosial (Jarmitia, Sulistiyani, Yulandari, Tattar, \& Santoso, 2017). Dukungan sosial yang diperoleh oleh individu akan membantunya dalam mengatasi permasalahan yang dihadapi (Herawati, Krisnatuti, \& Rukmayanti, 2012). Adanya dukungan sosial yang diperoleh akan meningkatkan kesejahteraannya. Dukungan sosial secara langsung berhubungan signifikan terhadap kesejahteraan (Rashid, Nordin, Omar, \& Ismail, 2011). Dukungan sosial dapat diperoleh dari berbagai pihak baik teman, kerabat, keluarga, asosiasi kerja, kelompok sosial, dan jaringan formal lainnya. Jika individu atau keluarga mendapatkan dukungan sosial maka keluarga mempunyai kesehatan fisik serta mental yang lebih baik sehingga tekanan ekonomi yang dialami dapat diatasi dengan coping yang baik dan kesejahteraan keluarga pun tercapai. Dukungan sosial yang diperoleh oleh individu dari lingkup sosialnya akan membantu individu tersebut mencapai kesejahteraannya (Rohmad \& Prastiti, 2015). Kesejahteraan adalah usaha untuk melepaskan diri dari tekanan, berupa kesulitan, kesukaran, dan gangguan untuk mencapai suatu keadaan yang relatif tercukupi (Iskandar, 2011). Kesejahteraan rumah tangga dipengaruhi oleh beberapa faktor, yaitu usia, pendidikan, status perkawinan, pekerjaan, tempat tinggal, ukuran rumah tangga, dan siklus hidup (Iskandar, 2011). Miskin atau tidak sejahtera dalam pandangan sosial sangat ditentukan oleh posisi dalam masyarakat yang dapat dilihat dari tingkat pemenuhan kebutuhan hidup keluarga. Kesejahteraan subjektif keluarga dapat dilihat dari kualitas hidup individu atau keluarga tersebut seperti perasaan baik atau rasa puas secara umum (Puspitawati, Simanjuntak, dan Hayati, 2012). Kesejahteraan subjektif menggambarkan penilaian seseorang terhadap kehidupannya yang mencakup indikator kesejahteraan fisik, sosial, dan psikologis (Puspitawati et al., 2012).

Tujuan penelitian ini adalah: 1) mengidentifikasi karakteristik individu dan keluarga, tekanan ekonomi, coping ekonomi, dukungan sosial, serta kesejahteraan perempuan kepala keluarga; 2) menganalisis pengaruh karakteristik individu dan keluarga, tekanan ekonomi, coping ekonomi, dan dukungan sosial terhadap kesejahteraan perempuan kepala keluarga.

\section{METODE}

Penelitian menggunakan desain cross-sectional dan diteliti secara kuantitatif yang dilakukan di Jawa Barat. Waktu pengambilan data dilakukan pada akhir bulan Oktober-November 2020. Kriteria responden adalah perempuan sebagai kepala keluarga yang bercerai minimal 1 tahun dan maksimal 5 tahun serta memiliki anak. 
Jumlah contoh sebanyak 100 orang diambil melalui metode non-probability voluntary sampling. Data yang digunakan adalah data primer yang didapat melalui penyebaran kuesioner melalui media sosial (WhatsApp).

Tekanan ekonomi merupakan kesulitan yang dirasakan keluarga terhadap permasalahan keuangan yang mengganggu kehidupan keluarga, merasa sulit menabung, pengeluaran lebih besar dari pendapatan, tidak punya cukup uang untuk biaya sekolah anak, dan merasa tertekan oleh masalah ekonomi yang dihadapi sehingga membutuhkan bantuan. Tekanan ekonomi terdiri dari tekanan ekonomi subjektif yang diukur menggunakan kuesioner yang dimodifikasi dari Hilton dan Devall (1997). Jumlah pertanyaan tujuh butir dengan nilai Cronbach's alpha 0,896. Coping ekonomi, merupakan suatu strategi atau cara yang dilakukan untuk menghadapi dan mengatasi masalah ekonomi yang dialami oleh keluarga dengan cara mengurangi konsumsi, mengonsumsi produk sendiri, mencari pekerjaan tambahan, menjual aset, dan mencari bantuan. Coping ekonomi diukur menggunakan kuesioner yang dimodifikasi dari Börner et al. (2015). Coping ekonomi dilihat dari lima dimensi, yaitu mengurangi konsumsi, mengonsumsi produk sendiri, mencari pekerjaan tambahan, menjual aset, dan mencari bantuan. Jumlah pertanyaan tujuh butir dengan nilai Cronbach's alpha 0,821. Dukungan sosial berupa dukungan nyata ataupun dukungan dalam bentuk penguatan dari lingkungan seperti keluarga besar, teman atau tetangga, dan komunitas yang terdiri dari indikator dukungan emosi, instrumen, informasi, dan penghargaan. Dukungan sosial menggunakan kuesioner Multidimensional Scale Perceived Social Support (Zimet, Dahlem, Zimet, \& Farley, 1988) yang dimodifikasi. Dukungan sosial dilihat dari tiga dimensi dukungan yaitu keluarga besar, tetangga, dan komunitas PEKKA. Setiap dimensi memiliki empat indikator, yaitu emosi, instrumen, informasi, dan penghargaan. Jumlah pertanyaan 25 butir dengan nilai Cronbach's alpha sebesar 0,834. Tekanan ekonomi, coping ekonomi, dan dukungan sosial diukur dengan menggunakan skala pilihan jawaban tidak pernah, kadang-kadang, dan sering. Kesejahteraan subjektif merupakan kepuasan terhadap tingkat pemenuhan kebutuhan dasar dan perkembangan kehidupan keluarga yang meliputi perasaan apakah senang, nyaman, dan tenang dalam menjalani kehidupan seharihari, memiliki makna hidup yang mana merasa bermanfaat bagi keluarga dan optimis untuk masa depan, serta merasakan kebahagiaan dalam hidup. Kesejahteraan subjektif diukur menggunakan kuesioner yang memiliki pertanyaan sebanyak tujuh buah dan dibagi menjadi tiga dimensi, yaitu perasaan, makna hidup, dan kebahagiaan hidup (Abdallah, Stoll, Eiffe, \& Ferdinand, 2013) dengan nilai Cronbach's alpha 0,910. Kuesioner ini diukur dengan menggunakan skala likert 1-3. Data yang telah dikumpulkan selanjutnya diolah dan dianalisis secara deskriptif serta inferensia yaitu uji regresi linier berganda.

\section{HASIL}

\section{Karakteristik Responden}

Usia responden berada pada kisaran 24-58 tahun dengan rata-rata 39,24 tahun. Lama responden menjadi kepala keluarga berada pada rentang 1-5 tahun dengan nilai rataratanya adalah 4,04 tahun. Rata-rata tingkat pendidikan responden adalah SMA dengan lama pendidikan berkisar antara 6 tahun (SD) hingga 16 tahun (S1). Sebagian besar $(88,0 \%)$ responden memiliki pekerjaan tidak tetap dengan pendapatan sebagian besarnya $(85,0 \%)$ di bawah UMP Jawa Barat. Sebagian besar $(90,0 \%)$ responden memiliki anggota keluarga sebanyak tiga orang dan terkategori keluarga kecil. Lebih dari setengah $(66,0 \%)$ responden memiliki rasio aset/utang dengan kategori aset lebih sedikit dibandingkan dengan utang yang dimiliki. Seluruh reponden memiliki utang $(100,0 \%)$.

\section{Tekanan Ekonomi}

Tekanan ekonomi subjektif responden memiliki rata-rata indeks 64,36 yang termasuk kategori sedang. Hal ini bermakna bahwa kadangkadang responden merasa membutuhkan bantuan, kadang-kadang pengeluaran keluarga lebih besar dari pada pendapatan, dan kadangkadang merasa tertekan ketika terjadi masalah ekonomi dalam keluarga. Hampir dari setengah responden mengalami tekanan ekonomi termasuk pada kategori tinggi (Tabel 1).

Tabel 1 Sebaran contoh berdasarkan kategori tekanan ekonomi subjektif dan nilai minimum, maksimum serta rataan indeks

\begin{tabular}{lr}
\hline \multicolumn{1}{c}{ Tekanan ekonomi subjektif } & Persentase (\%) \\
\hline Rendah $(<50)$ & 28,0 \\
Sedang $(50-75)$ & 30,0 \\
Tinggi $(>75)$ & 42,0 \\
\hline Total & 100,0 \\
\hline Minimal-Maksimal (indeks) & $14,3-100$ \\
Rata-rata \pm Standardeviasi (indeks) & $64,36 \pm 25,96$ \\
\hline
\end{tabular}


Responden menyatakan bahwa dirinya sering merasa terganggu dengan masalah keuangan yang dirasakan dan sering merasa sulit menyisihkan uang untuk ditabung. Selain itu, ada beberapa responden yang mengalami tekanan ekonomi pada kategori rendah. Responden menyatakan bahwa tidak pernah merasa kekurangan uang untuk beli buku pelajaran.

\section{Coping Ekonomi}

Hasil analisis menunjukan, rata-rata indeks responden dalam melakukan coping ekonomi terkategori sedang $(51,63)$. Lebih dari setengah $(53,0 \%)$ responden kadang-kadang melakukan penghematan dan lebih dari setengah $(63,0 \%)$ responden kadang-kadang meminjam atau berutang. Sebanyak 37 persen responden melakukan coping ekonomi pada kategori rendah. Selain itu, hampir dari setengah responden melakukan coping ekonomi pada kategori sedang $(43,0 \%)$. Sisanya, responden melakukan coping ekonomi terkategori tinggi $(20,0 \%)$. Coping ekonomi memiliki lima dimensi, yaitu mengurangi konsumsi, mengonsumsi produk sendiri, mencari pekerjaan tambahan, menjual aset, dan mencari bantuan. Dimensi coping ekonomi yang paling banyak dilakukan oleh responden serta memiliki rata-rata indeks yang paling tinggi dibandingkan dimensi lainnya adalah dimensi mencari pekerjaan tambahan $(64,50)$ (Tabel 2).

Mengurangi Konsumsi. Rata-rata indeks dimensi mengurangi konsumsi yang dilakukan responden termasuk kategori sedang $(63,17)$. Hampir dari setengah responden mengurangi konsumsi yang termasuk pada kategori rendah $(23,0 \%)$. Sisanya termasuk pada kategori sedang $(36,0 \%)$ dan tinggi $(41,0 \%)$. Hal ini dapat dilihat dari pernyataan responden yang menyatakan bahwa responden tidak pernah mengurangi uang jajan (20,0\%). Selain itu, sebagian besar responden juga menyatakan bahwa ketika ada masalah keuangan dalam keluarga, responden kadang-kadang mengurangi konsumsi makanan sehari-hari $(53,0 \%)$ dan sering melakukan penghematan saat belum mendapatkan uang/pemasukan $(65,0 \%)$.

Mengonsumsi Produk Sendiri. Rata-rata indeks dimensi mengonsumsi produk sendiri termasuk kategori sedang $(50,00)$. Hasil penelitian menujukkan bahwa hampir setengah responden menyatakan mengonsumsi produk sendiri yang termasuk pada kategori rendah $(42,0 \%)$ dan tinggi $(42,0 \%)$, serta sisanya termasuk pada kategori sedang $(16,0 \%)$. Hal ini dapat dilihat dari pernyataan bahwa responden kadang-kadang memanfaatkan pekarangan dengan menanam sayur mayur untuk dikonsumsi sendiri $(16,0 \%)$.

Mencari Pekerjaan Tambahan. Rata-rata indeks responden dalam dimensi mencari pekerjaan tambahan termasuk pada kategori sedang $(64,50)$. Hasil penelitian menunjukkan bahwa hampir setengah reponden mencari pekerjaan tambahan termasuk pada kategori tinggi $(48,0 \%)$ sementara sisanya termasuk pada kategori rendah $(19,0 \%)$ dan sedang $(33,0 \%)$. Hal ini dapat dilihat dari pernyataan bahwa responden sering melakukan pekerjaan lepas (contoh: ojek, tani, buruh, dll) untuk menambah penghasilan $(48,0 \%)$.

Menjual Aset. Rata-rata indeks responden dalam dimensi menjual aset termasuk pada kategori rendah $(28,00)$. Hasil penelitian menunjukan lebih dari separoh responden $(55,0 \%)$ menjual aset termasuk pada kategori rendah, sisanya termasuk pada kategori sedang $(34,0 \%)$ dan tinggi $(11,0 \%)$. Hal ini dapat dilihat dari pernyataan bahwa responden tidak pernah menjual aset (contoh: emas, peralatan rumah tangga, dII) untuk memenuhi kebutuhan keluarga apabila belum ada pemasukan $(55,0 \%)$.

Tabel 2 Sebaran contoh berdasarkan kategori coping ekonomi, minimum, maksimum dan rataan indeks dimensi

\begin{tabular}{|c|c|c|c|c|c|c|c|c|}
\hline \multirow{3}{*}{ Dimensi coping ekonomi } & \multicolumn{6}{|c|}{ Kategori } & \multirow{3}{*}{ Min-Maks } & \multirow{3}{*}{ Rata-rata $\pm S D$} \\
\hline & \multicolumn{2}{|c|}{$\begin{array}{c}\text { Rendah } \\
(<50)\end{array}$} & \multicolumn{2}{|c|}{$\begin{array}{l}\text { Sedang } \\
(50-75)\end{array}$} & \multicolumn{2}{|c|}{$\begin{array}{l}\text { Tinggi } \\
(>75)\end{array}$} & & \\
\hline & $\mathrm{n}$ & $\%$ & $\mathrm{n}$ & $\%$ & $\mathrm{n}$ & $\%$ & & \\
\hline Mengurangi konsumsi & 23 & 23,0 & 36 & 36,0 & 41 & 41,0 & $0-100$ & $63,17 \pm 30,55$ \\
\hline Mengonsumsi produk sendiri & 42 & 42,0 & 16 & 16,0 & 42 & 42,0 & $0-100$ & $50,00 \pm 46,06$ \\
\hline Mencari pekerjaan tambahan & 19 & 19,0 & 33 & 33,0 & 48 & 48,0 & $0-100$ & $64,50 \pm 38,47$ \\
\hline Menjual aset & 55 & 55,0 & 34 & 34,0 & 11 & 11,0 & $0-100$ & $28,00 \pm 34,32$ \\
\hline Mencari bantuan & 16 & 16,0 & 63 & 63,0 & 21 & 21,0 & $0-100$ & $52,50 \pm 30,46$ \\
\hline Total coping ekonomi & 37 & 37,0 & 43 & 43,0 & 20 & 20,0 & $7,1-100$ & $51,63 \pm 24,71$ \\
\hline
\end{tabular}


Mencari Bantuan. Hasil analisis menunjukkan, rata-rata indeks responden dalam dimensi mencari bantuan termasuk pada kategori sedang $(52,50)$. Selanjutnya, lebih dari separoh responden $(63,0 \%)$ termasuk pada kategori sedang, sisanya termasuk pada kategori rendah $(16,0 \%)$ dan tinggi $(21,0 \%)$. Hal ini dapat dilihat dari pernyataan responden bahwa kadang-kadang responden meminjam atau berhutang (contoh: uang atau sembako, dll) jika membutuhkan dari tetangga $(63,0 \%)$.

\section{Dukungan Sosial}

Hasil penelitian memperlihatkan bahwa ratarata indeks dukungan sosial termasuk pada kategori sedang $(58,19)$. Sebanyak 14 persen responden mendapatkan dukungan sosial yang termasuk pada ketegori rendah, lebih dari tiga perempat responden $(79,0 \%)$ mendapatkan dukungan sosial terkategori sedang, sedangkan 7 persen sisanya termasuk pada kategori tinggi. Dukungan sosial terdiri dari dukungan sosial keluarga besar, dukungan sosial tetangga/teman, dan dukungan sosial komunitas PEKKA. Dimensi dukungan sosial dari tetangga mempunyai rata-rata indeks terkategori sedang $(62,31)$. Dukungan sosial dari keluarga besar mempunyai rata-rata indeks terkategori sedang $(53,75)$ dan dukungan sosial dari Komunitas PEKKA termasuk kategori sedang $(58,50)$ (Tabel 3$)$.

Dukungan Sosial Keluarga Besar. Dukungan sosial keluarga besar secara keseluruhan mempunyai rata-rata indeks terkategori sedang $(53,75)$. Dukungan sosial keluarga besar dilihat dari dukungan secara emosi, instrumen, informasi, dan penghargaan. Responden mendapatkan dukungan sosial keluarga besar dengan rata-rata indeks terkategori tinggi yaitu dari segi penghargaan $(77,75)$. Responden menyatakan bahwa keluarga kecilnya dihargai $(57,0 \%)$ dan diterima $(62,0 \%)$ oleh keluarga besar. Dukungan sosial keluarga besar dengan rata-rata indeks terkategori rendah yaitu dari segi emosi $(48,50)$, instrumen $(39,00)$ dan informasi $(49,75)$. Responden menyatakan bahwa kadang-kadang keluarga besar memberikan solusi $(61,0 \%)$ dan kadang-kadang keluarga besar menghibur responden $(66,0 \%)$. Selain itu, kadang-kadang responden mengandalkan keluarga besar jika memerlukan pinjaman $(52,0 \%)$ dan kadang-kadang meminta bantuan keluarga besar dalam mengasuh anak $(47,0 \%)$. Adapun responden menyatakan bahwa kadang-kadang responden mencari informasi ke keluarga besar $(67,0 \%)$ dan kadang-kadang responden menawarkan informasi ke keluarga besar (72,0\%).

Tabel 3 Sebaran contoh berdasarkan variabel dukungan sosial, minimum, maksimum dan rataan indeks dimensi

\begin{tabular}{|c|c|c|c|c|c|c|c|c|c|}
\hline \multirow{3}{*}{\multicolumn{2}{|c|}{ Dimensi dukungan sosial }} & \multicolumn{6}{|c|}{ Kategori } & \multirow{3}{*}{ Min-Maks } & \multirow{3}{*}{ Rata-rata $\pm S D$} \\
\hline & & \multicolumn{2}{|c|}{$\begin{array}{c}\text { Rendah } \\
(<50)\end{array}$} & \multicolumn{2}{|c|}{$\begin{array}{c}\text { Sedang } \\
(51-75)\end{array}$} & \multicolumn{2}{|c|}{$\begin{array}{l}\text { Tinggi } \\
(>75)\end{array}$} & & \\
\hline & & $\mathrm{n}$ & $\%$ & $\mathrm{n}$ & $\%$ & $\mathrm{n}$ & $\%$ & & \\
\hline \multirow{4}{*}{ Keluarga besar } & Emosi & 25 & 25,0 & 63 & 63,0 & 12 & 12,0 & $0-100$ & $48,50 \pm 27,94$ \\
\hline & Intrumen & 46 & 46,0 & 46 & 46,0 & 8 & 8,0 & $0-100$ & $39,00 \pm 28,50$ \\
\hline & Informasi & 19 & 19,0 & 70 & 70,0 & 11 & 11,0 & $0-100$ & $49,75 \pm 25,99$ \\
\hline & Penghargaan & 5 & 5,0 & 40 & 40,0 & 55 & 55,0 & $0-100$ & $77,75 \pm 27,50$ \\
\hline \multicolumn{2}{|c|}{ Total keluarga besar } & 27 & 27,0 & 63 & 63,0 & 10 & 10,0 & $0-100$ & $53,75 \pm 21,25$ \\
\hline \multirow{4}{*}{ Tetangga } & Emosi & 3 & 3,0 & 76 & 76,0 & 21 & 21,0 & $0-100$ & $60,75 \pm 21,98$ \\
\hline & Intrumen & 24 & 24,0 & 73 & 73,0 & 3 & 3,0 & $0-100$ & $47,00 \pm 19,55$ \\
\hline & Informasi & 5 & 5,0 & 77 & 77,0 & 18 & 18,0 & $0-100$ & $59,75 \pm 22,16$ \\
\hline & Penghargaan & 1 & 1,0 & 35 & 35,0 & 64 & 64,0 & $25-100$ & $81,75 \pm 24,58$ \\
\hline \multicolumn{2}{|l|}{ Total tetangga } & 11 & 11,0 & 74 & 74,0 & 15 & 15,0 & $18,8-100$ & $62,31 \pm 15,35$ \\
\hline \multirow{4}{*}{$\begin{array}{l}\text { Komunitas } \\
\text { PEKKA }\end{array}$} & Emosi & 4 & 4,0 & 81 & 81,0 & 15 & 15,0 & $0-100$ & $57,50 \pm 17,78$ \\
\hline & Intrumen & 68 & 68,0 & 28 & 28,0 & 4 & 4,0 & $0-100$ & $30,00 \pm 24,10$ \\
\hline & Informasi & 2 & 2,0 & 79 & 79,0 & 19 & 19,0 & $0-100$ & $61,25 \pm 21,13$ \\
\hline & Penghargaan & 1 & 1,0 & 30 & 30,0 & 69 & 69,0 & $00-100$ & $85,25 \pm 23,33$ \\
\hline \multicolumn{2}{|c|}{ Total komunitas PEKKA } & 8 & 8,0 & 83 & 83,0 & 9 & 9,0 & $0-100$ & $58,50 \pm 13,57$ \\
\hline \multicolumn{2}{|c|}{ Total dukungan sosial } & 14 & 14,0 & 79 & 79,0 & 7 & 7,0 & $23,6-100$ & $58,19 \pm 11,91$ \\
\hline
\end{tabular}


Dukungan Sosial Tetangga/Teman. Secara keseluruhan responden mendapatkan dukungan sosial dari tetangga/teman dengan rata-rata indeks terkategori sedang $(62,31)$. Dukungan sosial tetangga/teman dilihat dari dukungan secara emosi, instrumen, informasi, dan penghargaan. Responden mendapatkan dukungan sosial dari tetangga/teman dengan rata-rata indeks termasuk kategori tinggi yaitu dari segi penghargaan $(81,75)$. Responden menyatakan bahwa sering merasa keluarga kecilnya dihargai $(64,0 \%)$ dan diterima $(64,0 \%)$ oleh tetangga/teman. Dukungan sosial dengan rata-rata indeks termasuk kategori sedang yaitu dari segi emosi $(60,75)$ dan informasi $(59,75)$. Responden menyatakan bahwa kadang-kadang tetangga/teman memberikan solusi terhadap masalah yang dihadapi $(74,0 \%)$ dan kadangkadang jika sedang sedih ada tetangga/teman yang bisa menghiburnya $(75,0 \%)$. Selain itu, responden menyatakan bahwa kadang-kadang mencari informasi ke tetangga atau teman agar dapat menolongnya $(75,0 \%)$ dan kadangkadang responden menawarkan informasi ke tetangga/teman yang membutuhkan $(70,0 \%)$. Dukungan dengan rata-rata indeks terkategori rendah terdapat pada dimensi instrumen $(47,00)$. Responden menyatakan bahwa kadang-kadang responden mengandalkan tetangga/teman jika memerlukan pinjaman (contoh: uang, barang, dII) $(77,0 \%)$ dan kadang-kadang mendapatkan bantuan dari tetangga/teman dalam mengasuh anak jika sewaktu-waktu dibutuhkan (73,0\%).

Dukungan sosial komunitas PEKKA. Secara keseluruhan responden mempunyai rata-rata indeks dukungan sosial komunitas PEKKA pada kategori sedang $(58,50)$. Dukungan sosial komunitas PEKKA dilihat dari dukungan secara emosi, instrumen, informasi, dan penghargaan. Dukungan sosial dengan rata-rata indeks yang termasuk kategori tinggi adalah dari segi penghargaan $(85,25)$. Responden merasa keluarga kecilnya sering dihargai $(73,0 \%)$ dan diterima $(70,0 \%)$ oleh komunitas PEKKA.
Dukungan sosial dengan rata-rata indeks terkategori sedang yaitu dari segi emosi $(57,50)$ dan informasi $(61,25)$. Responden menyatakan bahwa kadang-kadang komunitas PEKKA memberikan solusi $(83,0 \%)$, kadang-kadang memberikan perhatian $(76,0 \%)$, dan kadangkadang menghibur (76,0\%). Responden juga menyatakan bahwa kadang-kadang mencari $(75,0 \%)$ dan memberikan $(74,0 \%)$ informasi kepada komunitas PEKKA. Selain itu, dukungan sosial dengan rata-rata indeks termasuk kategori rendah adalah dari segi instrumen $(30,00)$. Responden menyatakan bahwa tidak pernah mengandalkan komunitas PEKKA ketika memerlukan pinjaman $(25,0 \%)$ dan tidak pernah meminta bantuan kepada komunitas PEKKA dalam mengasuh anak $(68,0 \%)$.

\section{Kesejahteraan Subjektif}

Kesejahteraan subjektif terdiri dari tiga dimensi yaitu perasaan, makna hidup, dan kebahagiaan. Secara keseluruhan, dapat dilihat pada Tabel 4 bahwa rata-rata indeks tingkat kesejahteraan subjektif responden termasuk pada kategori sedang $(58,11)$. Dimensi kesejahteraan subjektif yang memiliki rata-rata indeks termasuk tinggi dibanding dimensi yang lain adalah dimensi kebahagiaan $(59,50)$. Dimensi dengan rata-rata indeks termasuk kategori rendah adalah dimensi perasaan, sedangkan dimensi dengan rata-rata indeks terkategori sedang adalah dimensi makna hidup $(58,67)$.

Dimensi Perasaan. Pada dimensi perasaan, sebanyak tiga perempat responden $(75,0 \%)$ tergolong kepada kategori sedang dan sisanya termasuk pada kategori rendah $(8,0 \%)$ dan tinggi $(17,0 \%)$. Hal ini dapat dilihat dari pernyataan responden bahwa responden merasa senang dalam menjalani kehidupan sehari-hari $(77,0 \%)$, merasa nyaman dalam menjalani kehidupan sehari-hari $(78,0 \%)$, dan merasa tenang dalam menghadapi masalah kehidupan sehari-hari $(82,0 \%)$.

Tabel 4 Sebaran contoh berdasarkan variabel kesejahteraan subjektif, minimum, maksimum dan rataan dimensi

\begin{tabular}{|c|c|c|c|c|c|c|c|c|}
\hline \multirow{3}{*}{ Kesejahteraan subjektif } & \multicolumn{6}{|c|}{ Kategori } & \multirow{3}{*}{ Min-Maks } & \multirow{3}{*}{ Rata-rata $\pm S D$} \\
\hline & \multicolumn{2}{|c|}{$\begin{array}{c}\text { Rendah } \\
(<50)\end{array}$} & \multicolumn{2}{|c|}{$\begin{array}{l}\text { Sedang } \\
(51-75)\end{array}$} & \multicolumn{2}{|c|}{$\begin{array}{l}\text { Tinggi } \\
(>75)\end{array}$} & & \\
\hline & $\mathrm{n}$ & $\%$ & $\mathrm{n}$ & $\%$ & $\mathrm{n}$ & $\%$ & & \\
\hline Perasaan & 8 & 8,0 & 75 & 75,0 & 17 & 17,0 & $0-100$ & $56,17 \pm 20,47$ \\
\hline Makna hidup & 5 & 5,0 & 79 & 79,0 & 16 & 16,0 & $33,3-100$ & $58,67 \pm 16,66$ \\
\hline Kebahagian & 4 & 4,0 & 73 & 73,0 & 23 & 23,0 & $0-100$ & $59,50 \pm 24,30$ \\
\hline Total kesejahteraan & 11 & 11,0 & 70 & 70,0 & 19 & 19,0 & $11,1-100$ & $58,11 \pm 18,81$ \\
\hline
\end{tabular}


Tabel 5 Uji regresi linear berganda karakteristik, tekanan ekonomi, coping ekonomi, dan dukungan sosial terhadap kesejahteraan

\begin{tabular}{|c|c|c|c|c|}
\hline \multirow[b]{2}{*}{ Variabel } & \multicolumn{4}{|c|}{ Koefisien } \\
\hline & $\begin{array}{l}\text { Koefisien tidak } \\
\text { terstandarisasi }(B)\end{array}$ & Std.Eror & $\begin{array}{c}\text { Koefisien } \\
\text { terstandarisasi } \\
\text { beta }(\beta)\end{array}$ & Sig \\
\hline konstanta & 63,481 & 25,817 & & $0,016^{*}$ \\
\hline Usia (tahun) & 0,264 & 0,240 & 0,111 & 0,274 \\
\hline Lama pendidikan (tahun) & 0,543 & 1,977 & 0,026 & 0,784 \\
\hline Pekerjaan (0=tetap;1=tidak tetap) & $-11,515$ & 5,512 & $-0,200$ & $0,040^{*}$ \\
\hline 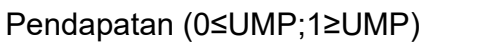 & 5,838 & 5,291 & 0,111 & 0,273 \\
\hline Besar keluarga (orang) & $-0,610$ & 1,471 & $-0,044$ & 0,680 \\
\hline Lama menjanda (tahun) & 2,540 & 1,412 & 0,165 & $0,076^{*}$ \\
\hline $\begin{array}{l}\text { Rasio aset/utang } \\
(0=\text { aset }>\text { utang; } 1=\text { aset<utang })\end{array}$ & $-5,906$ & 4,142 & $-0,149$ & 0,158 \\
\hline Tekanan ekonomi (indeks) & $-0,212$ & 0,186 & $-0,116$ & 0,258 \\
\hline \multicolumn{5}{|l|}{ Coping ekonomi (indeks) } \\
\hline Mengurangi konsumsi & 0,003 & 0,085 & 0,004 & 0,976 \\
\hline Mengonsumsi produk sendiri & $-0,055$ & 0,043 & $-0,135$ & 0,206 \\
\hline Mencari pekerjaan tambahan & $-0,112$ & 0,056 & $-0,230$ & $0,050^{*}$ \\
\hline Menjual aset & $-0,044$ & 0,058 & $-0,080$ & 0,449 \\
\hline Mencari bantuan & $-0,211$ & 0,070 & $-0,341$ & $0,004^{*}$ \\
\hline Dukungan sosial (indeks) & $-0,163$ & 0,259 & $-0,097$ & 0,530 \\
\hline \multicolumn{5}{|l|}{ Keluarga besar } \\
\hline Tetangga/teman & 0,673 & 0,208 & 0,440 & $0,002^{* *}$ \\
\hline Komunitas PEKKA & 0,176 & 0,154 & 0,127 & 0,256 \\
\hline Uji F & \multicolumn{4}{|c|}{3,548} \\
\hline Sig & \multicolumn{4}{|c|}{$0,000^{\star *}$} \\
\hline$R$ Square & \multicolumn{4}{|c|}{0,406} \\
\hline Adjusted R Square & \multicolumn{4}{|c|}{0,292} \\
\hline$n$ & \multicolumn{4}{|c|}{100} \\
\hline
\end{tabular}

Dimensi Makna Hidup. Pada dimensi makna hidup, lebih dari tiga perempat $(79,0 \%)$ responden termasuk pada kategori sedang. Sisanya termasuk pada kategori rendah $(5,0 \%)$ dan tinggi $(16,0 \%)$. Hal ini dapat dilihat dari pernyataan responden bahwa responden merasa mampu dalam menentukan keputusan bagi keluarga $(81,0 \%)$, merasa bermanfaat bagi keluarga $(86,0 \%)$, dan merasa optimis dengan masa depan $(67,0 \%)$.

Dimensi Kebahagiaan. Pada dimensi kebahagiaan, hampir dari tiga perempat $(73,0 \%)$ responden termasuk pada kategori sedang. Sisanya termasuk kategori rendah $(4,0 \%)$ dan tinggi $(23,0 \%)$. Hal ini dapat dilihat dari pernyataan responden bahwa merasa bahagia dengan kehidupan secara keseluruhannya $(73,0 \%)$.

Pengaruh Tekanan Ekonomi, Coping Ekonomi, dan Dukungan Sosial terhadap Kesejahteraan
Hasil analisis regresi linier model variabelvariabel terhadap kesejahteraan subjektif pada Tabel 5 menunjukkan angka Adjusted $R$ Square adalah 0,292 yang berarti model tersebut menjelaskan 29,2 persen model variabelvariabel dalam memengaruhi kesejahteraan subjektif dan sisanya sebanyak 70,8 persen dipengaruhi oleh variabel lain di luar penelitian ini.

Hasil penelitian ini menunjukkan bahwa pekerjaan $\quad(\beta=-0,200 ; \quad p=0,040) \quad$ memiliki pengaruh negatif signifikan terhadap tingkat kesejahteraan subjektif responden. Semakin dewasa umur responden maka tingkat kesejahteraan subjektif responden akan semakin meningkat. Setiap kenaikan satu satuan usia maka akan meningkatkan kesejahteraan subjektif sebesar 0,045 poin. Hasil penelitian juga menunjukkan bahwa lama menjanda $\quad(\beta=0,183 ; \quad p=0,049) \quad$ juga berpengaruh positif signifikan terhadap tingkat kesejahteraan subjektif responden. Semakin lama menjadi anggota PEKKA maka tingkat 
kesejahteraan subjektif yang dirasakan pun akan semakin meningkat. Pada setiap kenaikan satu satuan lama menjadi anggota PEKKA maka akan meningkatkan kesejahteraan subjektif responden sebanyak 0,049 poin. Selain itu, penelitian juga menunjukkan hasil bahwa rasio aset/utang $(\beta=-0,186 ; p=0,092)$ berpengaruh positif signifikan terhadap kesejahteraan subjektif responden. Semakin kecil utang dibandingkan dengan aset yang dimiliki maka akan meningkatkan kesejahteraan subjektif. Pada setiap kenaikan satu satuan rasio aset/utang maka akan meningkatkan kesejahteraan subjektif sebesar 0,092 poin.

Variabel coping ekonomi $(\beta=-0,346 ; p=0,012)$ menunjukkan pengaruh negatif signifikan terhadap kesejahteraan subjektif. Semakin banyak coping ekonomi yang dilakukan maka tingkat kesejahteraan subjektif pun akan semakin rendah. Setiap penurunan satu satuan coping ekonomi akan menurunkan tingkat kesejahteraan subjektif sebanyak 0,012 poin. Selain itu, variabel dukungan sosial $(\beta=0,274$; $\mathrm{p}=0,004)$ memiliki pengaruh positif sangat signifikan terhadap kesejahteraan subjektif. Semakin tinggi dukungan sosial yang diterima maka semakin meningkat pula tingkat kesejahteraan subjektif yang dirasakan. Setiap kenaikan satu satuan dimensi penghargaan akan meningkatkan kesejahteraan subjektif sebesar 0,004 poin.

\section{PEMBAHASAN}

Penelitian yang dilakukan terhadap responden perempuan kepala keluarga ini menunjukkan hasil bahwa rata-rata usia responden terkategori dewasa madya. Menurut Clark dan Oswal (2006), kategori dewasa madya menggambarkan titik terendah kesejahteraan subjektif individu. Hal ini tidak sejalan dengan hasil penelitian ini yang mana semakin dewasa umur responden maka tingkat kesejahteraan akan semakin meningkat. Rata-rata lama responden menjadi perempuan kepala keluarga adalah 4,04 tahun dengan minimal 1 tahun dan paling lama 5 tahun. Tingkat dan lama pendidikan yang ditempuh oleh responden ratarata hanya sampai jenjang Sekolah Menengah Atas (SMA). Tingkat pendidikan yang rendah berpengaruh terhadap jenis pekerjaan yang dimiliki (Herawati, Tyas, \& Trijayanti, 2017). Sebagian besar responden memiliki jenis pekerjaan yang tidak tetap. Pada umumnya perempuan kepala keluarga bekerja di sektor informal seperti buruh tani, pedagang, dan pengrajin (PEKKA \& SMERU, 2014). Adanya pekerjaan yang tidak tetap ini memberikan dampak kepada pendapatan yang didapatkan oleh responden. Sebagian besar (85,0\%) responden memiliki pendapatan di bawah garis UMP Jawa Barat atau kurang dari Rp1.810.351. Kesejahteraan keluarga sangat dipengaruhi oleh faktor internal, salah satunya adalah faktor pendapatan (Hayati \& Nasution, 2020). Selain pendapatan, faktor lain yang dapat memengaruhi tingkat kesejahteraan keluarga adalah jumlah anggota keluarga (Hayati \& Nasution, 2020). Hasil penelitian menunjukkan bahwa hampir seluruh responden memiliki ukuran keluarga pada kategori keluarga kecil yaitu rata-rata 3 anggota keluarga. Selain itu, seluruh responden memiliki utang namun responden rata-rata berada pada keadaan ekonomi dengan jumlah aset lebih sedikit dibanding utang.

Hasil penelitian menyatakan bahwa responden memiliki tekanan ekonomi subjektif yang termasuk pada kategori tinggi. Perempuan bercerai pada umumnya memiliki keadaan ekonomi yang sangat kronis dibandingkan lakilaki bercerai dan hal ini berdampak pada tingkat kemiskinannya (Leopold, 2018). Keluarga yang dipimpin oleh perempuan bercerai memiliki keadaan ekonomi negatif atau rendah (Bröckel \& Andrew, 2015). Coping ekonomi responden dalam penelitian ini termasuk pada kategori sedang. Dimensi coping ekonomi yang paling sering dilakukan adalah mencari pekerjaan tambahan, sedangkan dimensi yang paling sedikit dilakukan adalah menjual aset. Salah satu penyebab hal ini biasanya ialah keterbatasan aset yang dimiliki (Silitonga, Puspitawati, \& Muflikhati, 2018). Strategi koping sangat dibutuhkan dalam kehidupan rumah tangga terlebih dalam hal koping ekonomi dan ini merupakan strategi rasional (Itzigsohn, 1995).

Pada penelitian ini dukungan sosial responden dari keluarga besar, tetangga, dan komunitas PEKKA berdasarkan dimensi dukungan emosi, instrumen, informasi, dan penghargaan secara berturut-turut termasuk pada kategori sedang, sedang, sedang dan tinggi. Sebagian besar responden menerima dukungan sosial secara emosi lebih banyak dibandingkan dengan dukungan instrumen, informasi, dan penghargaan. Dukungan sosial emosi yang diterima memberikan rasa nyaman dan bantuan bagi individu yang membutuhkan. Responden menerima dukungan sosial emosi yang besar dari lingkungan sekitarnya sehingga menguatkan keyakinannya dalam menghadapi dan mengatasi masalah hidup dan menerima kondisi keluarga dengan rasa syukur. Dukungan sosial dibangun sebagai mekanisme protektif dengan efek utama dan penyangga 
yang dapat berdampak pada kesejahteraan keluarga (Armstrong, Birnie, \& Ungar, 2005). Hasil kesejahteraan subjektif secara keseluruhan menunjukkan bahwa lebih dari tiga perempat responden termasuk pada kategori sedang. Pasca perceraian, keluarga yang dipimpin oleh perempuan dalam hal konsekuensi kesejahteraan subjektif lebih rentan dalam jangka waktu lama dibandingkan keluarga yang dipimpin oleh laki-laki bercerai yang sebagian besar hanya dalam jangka waktu pendek (Leopold, 2018). Sebagian besar keluarga yang dipimpin oleh perempuan terutama perempuan janda baik di desa maupun kota biasanya bermasalah dalam hal kesejahteraan ekonomi (Appleton, 1996).

Kesejahteraan keluarga responden perempuan kepala keluarga dipengaruhi secara positif signifikan oleh pekerjaan, lama menjanda, dan coping ekonomi serta dukungan sosial. Keluarga yang dipimpin oleh perempuan membutuhkan waktu yang lama dalam hal konsekuensi agar tingkat kesejahteraan subjektifnya meningkat (Leopold, 2018).

Berdasarkan hasil uji regresi liner berganda, coping ekonomi berpengaruh negatif terhadap kesejahteraan subjektif. Keluarga yang sering melakukan coping ekonomi mengindikasikan kesejahteraan keluarga tersebut rendah (Dercon, 2002). Salah satu yang menimbulkan keadaan stres adalah masalah keuangan dan coping ekonomi merupakan cara dalam mengatasi kritis keuangan yang dialami oleh keluarga (Yilma et al., 2014). Semakin sedikit strategi coping yang digunakan oleh keluarga mengindikasikan bahwa tingkat kesejahteraan yang dimiliki semakin meningkat (Rosidah, Hartoyo, \& Muflikhati, 2012). Selain itu, dukungan sosial memiliki pengaruh positif terhadap kesejahteraan subjektif. Dengan adanya dukungan sosial maka individu dapat mengatasi masalahnya dengan lebih mudah sehingga kesejahteraan pun tercapai (Rohmad, 2014). Dukungan sosial merupakan kebutuhan mendasar bagi individu untuk melanjutkan hubungan sosial, mengatasi kesepian, beradaptasi dengan teman-teman, dan mempertahankan stabilitas psikologis (Gunuc \& Dogan, 2013). Penelitian Eva, Shanti, Hidayah, dan Bisri (2020) menemukan bahwa dukungan sosial merupakan salah satu prediktor kesejahteraan bagi individu atau keluarga. Semakin baik dukungan sosial yang diterima oleh seseorang maka akan semakin tinggi juga tingkat kesejahteraannya dan sebaliknya, semakin sedikit dukungan sosial yang didapatkan maka akan semakin rendah tingkat kesejahteraannya (Tarigan, 2018). Dukungan sosial ini sangat berpengaruh terhadap tingkat kesejahteraan bagi perempuan yang memiliki peran ganda yaitu perempuan yang mencari nafkah dan berperan sebagai seorang ibu (Indriani \& Sugiasih, 2016). Individu yang bercerai mati ataupun bercerai hidup samasama dapat memiliki kesejahteraan subjektif yang tinggi dan ini tergantung pada cara individu tersebut menyikapi setiap kejadian atau masalah yang dihadapinya; semakin baik dan tepat tindakan individu tersebut maka semakin tinggi kesejahteraan subjekifnya (Miranda \& Amna, 2017). Kesejahteraan tergantung pada faktor biologis, lingkungan dan diri sendiri individu tersebut baik laki-laki maupun perempuan (Batz \& Tay, 2018).

\section{SIMPULAN DAN SARAN}

Karakteristik seperti pekerjaan dan lama menjanda berpengaruh positif dan negatif signifikan terhadap kesejahteraan subjektif. Coping ekonomi berpengaruh negatif signifikan terhadap kesejahteraan subjektif. Dukungan sosial juga berpengaruh positif siginifikan terhadap kesejahteraan subjektif. Pekerjaan dan rentang lama menjanda menjadi faktor yang dapat memengaruhi tingkat kesejahteraan yang dimiliki. Kesejahteraan pun dapat diperoleh jika perempuan kepala keluarga tidak memiliki utang. Semakin sedikit coping ekonomi yang dilakukan oleh perempuan kepala keluarga dan semakin banyak dukungan sosial yang didapatkan akan meningkatkan tingkat kesejahteraannya.

Perempuan kepala keluarga sebaiknya mengurangi utang agar tekanan ekonomi yang dirasakan akan semakin berkurang sehingga kesejahteraan dan kepuasan keluarga tetap terjaga dan terpenuhi. Hal ini dapat dilakukan dengan cara mengurangi konsumsi, mengonsumsi produk sendiri, dan mencari pekerjaan tambahan serta mendapatkan bantuan dan dukungan dari lingkungan tempat tinggalnya. Penelitian terhadap perempuan kepala keluarga ini sebaiknya dilakukan secara langsung atau tatap muka agar bisa mendapatkan informasi lebih banyak seputar keadaan kehidupan perempuan kepala keluarga ini. Hal ini juga bertujuan untuk mempermudah komunikasi dengan perempuan kepala keluarga.

Adapun kelemahan dan keterbatasan dalam penelitian ini salah satunya adalah karakteristik atau kriteria anak dari subjek penelitian. Selain itu, penelitian ini tidak bisa mendapatkan informasi yang lebih rinci mengenai keadaan kehidupan responden perempuan kepala 
keluarga. Penelitian dilakukan secara online sehingga membatasi komunikasi dengan responden karena sebagian responden tidak memiliki telepon genggam sendiri dan kurang memahami teknologi.

\section{DAFTAR PUSTAKA}

Abdallah, S., Stoll, L., Eiffe, F., \& Ferdinand, F. (2013). Quality of life in Europe: Subjective well-being. European Foundation for the Improvement of Living and Working Conditions: Cornell University ILR Scholl. Retrieved from https://www.eurofound.europa.eu/publicati ons/report/2013/quality-of-life-socialpolicies/quality-of-life-in-europesubjective-well-being

Appleton, S. (1996). Women-headed households and household welfare: An empirical deconstruction for Uganda. World Development, 24(12), 1811-1827. doi:10.1016/S0305-750X(96)00089-7

Armstrong, M. I., Birnie, L. S., \& Ungar, M. T. (2005). Pathways between social support, family well being, quality of parenting, and child resilience: What we know. Journal of Child and Family Studies, 14(2), 269-281. doi:10.1007/s10826-005-5054-4

Batz, C., \& Tay, L. (2018). Gender differences in subjective well-being. In E. Diener, $\mathrm{S}$. Oishi, \& L. Tay (Eds.), Handbook of wellbeing. Salt Lake City, UT: DEF Publishers.

[BPS] Badan Pusat Statistik. (2018). Jumlah Nikah, Talak dan Cerai, serta Rujuk (Pasangan Nikah), 2014-2016. Retrieved from

https://www.bps.go.id/indicator/27/176/1/ju mlah-nikah-talak-dan-cerai-sertarujuk.html

[BPS] Badan Pusat Statistik. (2020). Jumlah Rumah Tangga 2009-2019. Retrieved from Bps.go.id. https://www.bps.go.id/statictable/2012/04/ 19/1604/persentase-rumah-tanggamenurut-provinsi-daerah-tempat-tinggaldan-jenis-kelamin-kepala-rumah-tangga2009-2021.html

Börner, J., Shively, G., Wunder, S., \& Wyman, M. (2015). How do rural households cope with economic shocks: Insights from global data using hierarchical analysis. Journal of Agricultural Economics, 66(2), 392-414. doi:10.1111/1477-9552.12097

Bröckel, M., \& Andreß, H. J. (2015). The economic consequences of divorce in germany: What has changed since the turn of the millennium?. Comparative Population Studies, 40(3), 277-312. doi:10.12765/CPoS-2015-04en

Clark, A. E., \& Oswald, A. J. (2006). The curved relationship between subjective well-being and age. Paris-Jourdan Sciences Economiques, 1-14. Retrieved from https://halshs.archivesouvertes.fr/halshs-00590404

Dar, T. B. (2018). Analysis of the femaleheaded households, situation in India with special reference to Jammu and Kashmir. International Journal of Research \& Review, 5(9), 43-51.

Dercon, S. (2002). Income risk, coping strategies and safety nets. World Bank Research Observer, 17(2), 141-166. doi:10.1093/wbro/17.2.141

Eva, N., Shanti, P., Hidayah, N., \& Bisri, M. (2020). Pengaruh dukungan sosial terhadap kesejahteraan psikologis mahasiswa dengan religiusitas sebagai moderator. Jurnal Kajian Bimbingan dan Konseling, 5(3), 122-131. doi:10.17977/um001v5i32020p122

Gunuc, S., \& Dogan, A. (2013). The relationships between Turkish adolescents' Internet addiction, their perceived social support and family activities. Computers in Human Behavior, 29(6), 2197-2207. doi:10.1016/j.chb.2013.04.011

Hayati, \& Nasution, E. S. (2020). Influencing factors to the family Welfare in Mulyasejati Village torwards citarum harum. KnE Social Sciences, 194-205. doi:10.18502/kss.v4i14.7873

Herawati, T., Krisnatuti, D., \& Rukmayanti, I. Y. (2012). Dukungan sosial dan ketahanan keluarga peserta dan bukan peserta program nasional pemberdayaan masyarakat (PNPM) mandiri. Jurnal IImu Keluarga dan Konsumen, 5(1), 1-10. doi:10.24156/jikk.2012.5.1.1.

Herawati, T., Tyas, F. P., \& Trijayanti, L. (2017). Tekanan ekonomi, strategi koping, dan ketahanan keluarga yang menikah usia muda. Jurnal Ilmu Keluarga dan Konsumen, 10(3), 181-191. doi:10.24156/jikk.2017.10.3.181

Hilton, J. M., \& Devall, E. L. (1997). The family economic strain scale: Development and evaluation of the instrument with singleand two-parent families. Journal of Family and Economic Issues, 18(3), 247-271. doi:10.1023/A:1024974829218 
Indriani, D., \& Sugiasih, I. (2016). Dukungan sosial dan konflik peran ganda terhadap kesejahteraan psikologis karyawati PT. Sc Enterprises Semarang. Jurnal Proyeksi, 11(1), 46-54. doi:10.30659/jp.11.1.46-54

Iskandar, A. (2011). Analisis praktek manajemen sumberdaya keluarga dan dampaknya terhadap kesejahteraan keluarga di Kabupaten dan Kota Bogor (Disertasi). Sekolah Pascasarjana IPB, Bogor, Indonesia.

Itzigsohn, J. (1995). Migrant remittances, labor markets, and household strategies: A comparative analysis of low-income household strategies in the Caribbean Basin. Social Forces, 74(2), 633-655. doi:10.2307/2580495

Jarmitia, S., Sulistiyani, A., Yulandari, N., Tattar, F. M., \& Santoso, H. (2017). Hubungan antara dukungan sosial dengan kepercayaan diri pada penyandang disabilitas fisik di SLB Kota Banda Aceh. Psikoislamedia: Jurnal Psikologi, 1(1), 6169.

doi:10.22373/psikoislamedia.v1i1.1483

[Kemenag] Kementerian Agama. (2019). Tingkat Perceraian di Indonesia. Retrieved from https://kemenag.go.id/berita/read/507618

Leopold, T. (2018). Gender differences in the consequences of divorce: A study of multiple outcomes. Demography, 55(3), 769-797. doi:10.1007/s13524-018-0667-6

Miranda, N., \& Amna, Z. (2017). Kesejahteraan subjektif pada individu bercerai: Studi kasus pada individu dengan status cerai mati dan cerai hidup. Jurnal Psikoislamedia, 2(1), 12-22. Retrieved from https://jurnal.arraniry.ac.id/index.php/Psikoislam/article/vi ew/1820/1358

Parson, T. (1937). The structure of social action. New York, US: McGraw-Hill Book Company.

Puspitawati, H., Putri, A. C., Titipani, A., \& Khasanah, M. N. (2019). Kontribusi ekonomi perempuan, tekanan ekonomi, dan kesejahteraan keluarga pada keluarga nelayan, dan keluarga buruh tani bawang merah. Jurnal IImu Keluarga dan Konsumen, 12(2), 87-99. doi:10.24156/jikk.2019.12.2.87

Puspitawati, H., Simanjuntak, M., \& Hayati, L. (2012). Kontribusi ekonomi dan peran ganda perempuan serta pengaruhnya terhadap kesejahteraan subjektif. Jurnal
IImu Keluarga dan Konsumen, 5(1), 1118. doi:10.24156/jikk.2012.5.1.11

PEKKA, SMERU. (2014). Menguak keberadaan dan kehidupan perempuan kepala keluarga. Jakarta, ID: Lembaga Penelitian SMERU.

Raharjo, I. T., Puspitawati, H., \& Krisnatuti, D. (2015). Tekanan ekonomi, manajemen keuangan, dan kesejahteraan pada keluarga muda. Jurnal IImu Keluarga dan Konsumen, $\quad 8(1), \quad 1-11$. doi:10.24156/jikk.2015.8.1.38.

Raz, I. S., \& Bryant, P. (1990). Social Background, phonological awareness and children's reading. British Journal Psychology, 8, 209-225. doi:10.1111/j.2044-835X.1990.tb00837.x

Rashid, W. E. W., Nordin, M. S., Omar, A., \& Ismail, I. (2011). Social support, workfamily enrichment and life satisfaction among married nurses in health service. International Journal of Social Science and Humanity, 1(2), 150-155. doi:10.7763/ijssh.2011.v1.26

Robila, M., \& Krishnakumar, A. (2005). Effects of economic pressure on marital conflict in Romania. Journal of Family Psychology, 19(2), 246-251. doi:10.1037/08933200.19.2.246

Rohmad. (2014). Hubungan antara dukungan sosial dengan kesejahteraan subjektif pada mahasiswa Fakultas Psikologi Universitas Muhammadiyah Surakarta. Naskah Publikasi, 1-18. Retrieved from http://eprints.ums.ac.id/31979/9/02.\%20N askah\%20Publikasi.pdf

Rohmad, \& Pratisti, W. D. (2015). Dukungan sosial dan kesejahteraan subjektif mahasiswa Fakultas Psikologi Universitas Muhammadiyah Surakarta. In Proceeding Seminar Nasional (pp. 219-227). Retrieved from http://hdl.handle.net/11617/6536

Rosidah, U., Hartoyo, H., \& Muflikhati, I. (2012). Kajian strategi koping dan perilaku investasi anak pada keluarga buruh pemetik melati gambir. Jurnal IImu Keluarga dan Konsumen, 5(1), 77-87. doi:10.24156/jikk.2012.5.1.77

Sabania, H., \& Hartoyo. (2016). Economic pressure, livelihood strategy, and family well-being in Cimanuk Watershed, Garut and Indramayu, West Java, Indonesia. Journal of Family Sciences, 1(1), 24-38. doi:10.29244/jfs.1.1.24-38. 
Silitonga, M., Puspitawati, H., \& Muflikhati, I. (2018). Modal sosial, coping ekonomi, gejala stress suami dan kesejahteraan subjektif keluarga pada keluarga TKW. Jurnal Kesejahteraan Keluarga dan Pendidikan, 5(1), 20-30. doi:10.21009/JKKP.051.03

Tarigan, M. (2018). Hubungan dukungan sosial dengan subjective well-being pada remaja yang memiliki orangtua tunggal. Jurnal Diversita, 4(1),

doi:10.31289/diversita.v4i1.1565
Yilma, Z., Mebratie, A., Sparrow, R., Abebaw, D., Dekker, M., Alemu, G., \& Bedi, A. S. 2014. Coping with shocks in rural Ethiopia. Journal of Development Studies, 50(7), 1009-1024. doi:10.1080/00220388.2014.909028

Zimet, G. D., Dahlem, N. W., Zimet, S. G., \& Farley, G. K. (1988). The multidimensional scale of perceived social support. Journal of Personality Assessment, 52(1), 30-41. doi:10.1207/s15327752jpa5201_2 